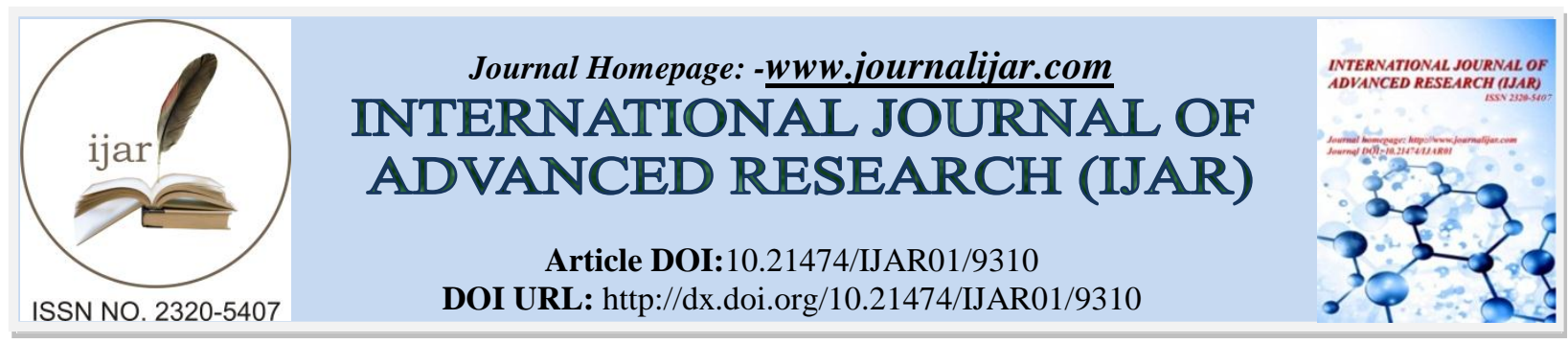

RESEARCH ARTICLE

\title{
AN AYURVEDIC MANAGEMENT OF AMLAPITTA A REVIEW.
}

Dr.Neha Karnavat and Dr.Abhilasha Sahu.

P.G.Scholar, Dept. Of Kayachikitsa, Govt. Dhanwantari Ayurvedic College and Hospital, Ujjain, M.P., INDIA.

\section{Manuscript Info}

Manuscript History

Received: 15 April 2019

Final Accepted: 17 May 2019

Published: June 2019

Key words:-

amlapitta, hyperacidity, swamarg chikitsa.
Abstract

Modern era's changing life style along with changing food culture and depending upon one's body constitution Amlapitta is one of the most common disease. The stomach normally secrets acid that is essential in the digestive process. When there is excess production of acid in the stomach, it results in the condition known as Hyperacidity. Pitta vardhak ahar vihar is the only reason for amlapitta. It can be managed through pitta shaman with vaman and virechan because according to our acharyas it occurs due to vitiation of kafa pitta doshas. swamarg chikitsa is described for the treatment of amlapitta.

Copy Right, IJAR, 2019,. All rights reserved.

\section{Introduction:-}

Hyperacidity is known to affect almost $70 \%$ of the population and new research now shows it to be the precursor for not just peptic ulcer, but also cancer of the stomach and the oesophagus. In its natural, healthy state, our body is slightly alkaline, the opposite of acidic. If we could only maintain this state, many of the physical and emotional problems that plague us such as fatigue, headache, and chronic illness might rarely or never appear. Our stomach normally secrets acid, this acid helps in the breakdown of food during digestion. When excess acid is produced in the stomach it results in hyperacidity. Hyperacidity is characterized by a deeply placed burning pain in the chest, behind the sternum which is commonly known as heartburn.

In modern medicine the number of medicines are available for the treatment of hyperacidity like proton pump inhibitor, H2 blocker, Antacids, prostaglandin etc. but these drugs carry their own side effects like headache, diarrhoea, dizziness, allergic reactions etc. and still there are no any permanent cure are available and patient has to suffer from it. So it is necessary to search permanent cure for it without any side effects. In this way some remedies are mentioned by our acharyas such as vaman, virechan, basti, etc.

\section{Aetiopathogenesis-}

When a person with a pre existing tendency for excessive pitta secretion (habitually) takes incompatible, unhygienic, excessively sour, heart burn producing and pitta vitiating food and drinks there is malsecretion of pitta.

\author{
Clinical features- \\ 1. Dyspepsia \\ 2. Fatigue \\ 3. Nausea \\ 4. Acrid and sour eructation \\ 5. Feeling of heaviness
}

Corresponding Author:-Neha Karnavat.

Address:-P.G.Scholar, Dept. Of Kayachikitsa, Govt. Dhanwantari Ayurvedic College and Hospital, Uiiain, M.P., INDIA. 
6. Burning sensation in the heart and throat

7. Anorexia

\section{Causes/Nidan-}

1. Incompatible, rotten, sour, hot, unctuous food-aggrevation of pitta

2. Eating before the digestion of previous meal-manifastion of ama.

3. Suppression of natural urges.

4. Day time sleeping after eating

5. Drinking water in between food eating

6. Stale food consumption

\section{Samprapti-}

Nidan sevan

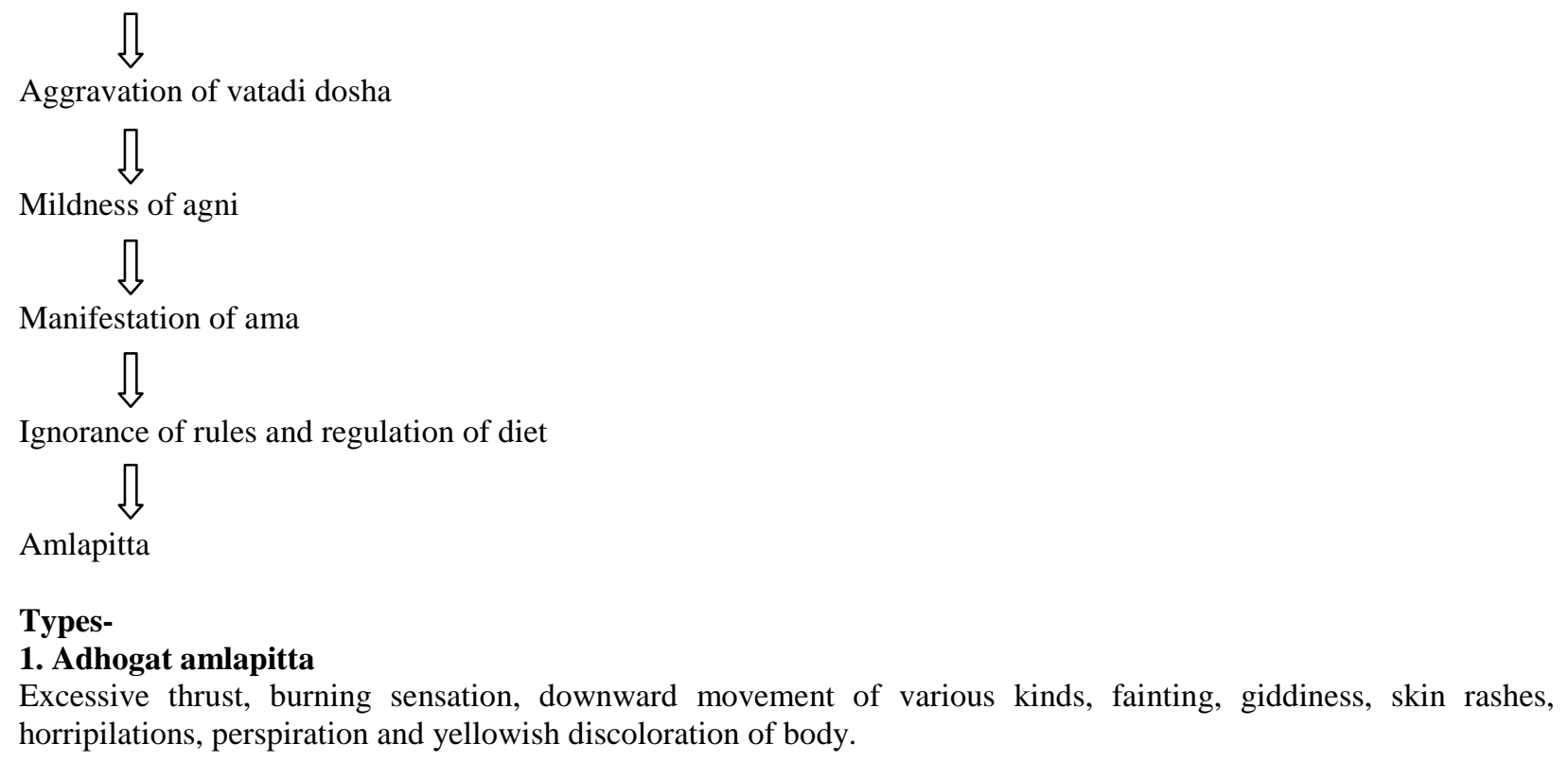

\section{Urdhvagat amlapitta}

1. Vomiting which is a green, yellow, blue, black, red colored sour substance.It resembles like mutton washed water.

2. Patient vomits during digestion of food or in empty stomach

3. Burning sensation in throat, chest, and upper abdomen, palms, soles

4. Headache

5. Loss of appetite

6. Itching

\section{Classification of amlapitta based on predominance of doshas-}

1. Vataj

2. Vat-kafaj

3. Kafaj

4. Kaf-pattaj

\section{Investigation-}

1. Gastroscopy (upper gastro intestinal endoscopy)

2. Oesophageal ph monitering

3. Barium meal x-ray

4. Serology and Histology for H-pylori

\section{Complication-}


1. Gastric ulcer

2. Chronic gastritis

3. IBS

4. Duodenitis

5. Anaemia

\section{Chikitsa sutra-}

1. Vaman followed by mild virechan should be administered.

2. Thereafter susnigdha anuvasan basti should be applied. (In chronic cases according to dosha)

3. In sansargaj amlapitta after shodhan, shaman measure in terms of drugs and diet should be applied considering the association of doshas.

4. In urdhwa and adho types, doshas should be eliminated with vaman and virechan respectively.

\section{Shaman chikitsa-}

1. Nidan parivarjan

2. Khand amalaki

3. Shatavari ghrit

4. Narikel khand

5. Sutshekhar ras

6. Lilavilas ras

7. Avipattikar churna

8. Kapard bhasm

\section{Pathya/apathya-}

1. Avoid long gaps between the meals

2. Avoid late night work

3. Drink sufficient water

4. Regular exercise

5. Avoid spicy, oily and fried food

6. Avoid arahar and urad daal and ground nuts

7. Take coconut water

8. Take watermelon juice

9. Avoid alcohole and smoking

10. Avoid curd

\section{Conclusion:-}

As we can see now a day's peoples are very busy in their works so they have to take instant, oily and fermented food and they do not live a healthy life so they have to suffer from hyperacidity .In this way through Ayurveda we can manage effectively amlapitta with panchakarma an follow dincharya and ritucjarya rules and some shaman chikitsa.

\section{Refrences:-}

1. Madhavanidanam, Rogaviniscaya of madhavakara, Prof.K.R.Srikantha Murthy,Publisher-Chaukhambha Orientalia, Varanasi, Fourth Edition-2001

2. Yogaratnakar vol.second, Dr.Madham Shetty, Suresh Babu, Publication-Chaukhamba Sanskrit Series Office, Varanasi, First Edition-2005

3. Madhavnidana, Rogaviniscaya, Ayurvedic Clinical Diagnosis, G.D.Singhal, S.N.Tripathi, K.R.Sharma, Publication-Chaukhamba Sanskrit Pratisthan, Delhi

4. A Text book of Kayachiktsa, Dr. P.S. Byadgi, Dr. A.K.Pandey, Publication- Chaukhambha -New Delhi, First Edition-22014

5. www.webmd.com

6. www.healthline.com

7. www.wikipedia.org 